\title{
Investigation of railway wheelset profile wear by using computer simulation
}

\author{
Lukáš Smetanka ${ }^{1}$, Slavomír Hrček ${ }^{1}$, and Pavol Št’astniak ${ }^{2, *}$ \\ ${ }^{1}$ University of Žilina, Faculty of Mechanical Engineering, Department of Design and Mechanical \\ Elements, Univerzitná 8215/1, 01026 Žilina, Slovak Republic \\ ${ }^{2}$ University of Žilina, Faculty of Mechanical Engineering, Department of Transport and Handling \\ Machines, Univerzitná 8215/1, 01026 Žilina, Slovak Republic
}

\begin{abstract}
The wear of rails and wheels is important problem in rail traffic. The change of the shape of the wheel profile has not only a great influence on the dynamic properties of the vehicle (like stability, safety by passing curved tracks, etc.), but also affects the ride comfort of passengers and environmental insults, in extreme cases it can cause rail derailment. One of the ways to predict these undesired conditions are computer aided simulation analyses. In this article are presented results of wheel profile wear by Archard wear law, when the vehicle of type Model A was driving in track by constant velocity of $30 \mathrm{~m} / \mathrm{s}$. The vehicle was traveling along track where the rail profile was defined by standard (UIC 60 profile) with cant of 1:40, or the track profile really measured on the track, the profile S 91700_16 with the cant of 1:20. Simulations were realized by SIMPACK software.
\end{abstract}

Keywords: wear, wheelset profile, computer simulation

\section{Introduction}

Wear belongs to the degradation processes, where material is lost from one or both surfaces of contact shapes of rigid bodies. Relative movement of the contact surfaces can directly lead to destroying of the component, or occurs disruption of the surface leading to the subsequent failure. Several factors influence the wear resistance, mostly: design solution, manufacturing process of component, operating conditions, material properties, thermal and thermalchemical processing etc. The contact problem is characterized by large plastic deformation. On other side is wear caused by the application of the cyclic loading of the component, the nucleation of the crack and its spreading into the final state of the fracture of the material. This means that a worn fracture occurs after several thousand cycles, which correspond to the fatigue life of the loaded component $[1,2]$.

During the operation of the railway transport, both wheel and rail wear occur, either due to normal operation or failure. With regard to the type of wear, the wear of rolling stock is based on the character of friction and also on the basis of cyclic fatigue. Over time the process of fatigue become separate scientific area named RCF (Rolling Contact Fatigue) [3-6].

\footnotetext{
* Corresponding author: pavol.stastniak@,fstroj.uniza.sk

Reviewers: Michał Bartyś, Krzysztof Talaśka
} 
The dynamic behaviour of rail vehicles on the track is significantly affected by the interaction between the wheel and the rail. In the depth of the examined issue is an understanding of the contact between the wheels and the rails. There are problems in this more in-depth study which stand alone are broad scientific areas. One of the most important areas with significant influence on geometry change and thus the change in contact conditions is undoubtedly the wear and related geometry changes of one part of the contact pair or both, such as the corrugation of the track and its irregularity, changes in friction and slip ratio or changes in vertical and longitudinal forces of the contact pair, etc. The impact of wear certainly affects also the acoustic and vibrational expression of the car on the rail, which, by increasing the negative side, devastates the environmental environment around the tracks $[1,7]$.

\section{Archard wear law in SIMPACK software}

According to several literary sources, there are three main trends in the development of the wear, patterns from the middle to the end of the twentieth century and they are: based on empirical approach, based on a contact mechanics approach and based on a reflex mechanics approach. An irreplaceable and important factor in wear is friction. The hypothesis suggests:

$$
F_{F}=\mu \cdot F_{N}
$$

where:

$-F_{F}$ is frictional force,

$-\mu$ is frictional coefficient,

- $F_{N}$ is applied normal force.

This frictional equation is based on two basic assumptions, first is approach that the stress distribution is independent to normal load and second that the applied load is proportional to real contact area.

We knows more wear laws which were then development and modified, but all of them are based on basic theories from authors like Reye (1860), Tabor (1939), Holm (1946) a Archard (1953) [8,9].

The supplement for wear determination is in SIMPACK software embedded to the module SIMPACK RAIL, it is therefore the determination of wear in the contact wheel-rail pair, where are the contact stresses solved by using the Kalker method named FASTSIM [10-12]. The developer motivated the application of supplement mainly to the issue of safety and maintenance, as is known, wheels and rails are subjected to wear and rolling contact fatigue (RCF) throughout their lifecycle, due the forces acting during frequent rail traffic. Considering that there are many different waste laws and RCF, the module has an open structure that makes it possible to implement the necessary changes to achieve the preferred type of wear. The SIMPACK software offers two different laws of wear and tear for simulation: Archard wear law and Krause/Poll wear law.

Archard wear law is for the SIMPACK software based on the following equation:

$$
V=\frac{N \cdot \Delta s}{H} \cdot\left\{\begin{array}{cccc}
k_{1} & \text { if } p>f H & \text { (seizure) } \\
k_{2} & \text { if } p \leq f H \text { and } v_{s} \leq v_{1} & \text { (mild 1) } \\
k_{3} & \text { if } p \leq f H \text { and } v_{1}<v_{s} \leq v_{2} & \text { (severe) } \\
k_{4} & \text { if } p \leq f H \text { and } v_{2}<v_{s} & \text { (mild 2) }
\end{array}\right.
$$

where:

- $V$ - wear volume $\left[\mathrm{m}^{3}\right]$,

- $N$ - normal contact force [N],

- $\Delta s$ - sliding distance $[\mathrm{m}]$,

- $H$ - hardness of the softer material in contact pair [MPa], 
- $k_{l}-k_{4}$ wear coefficients, (seizure, mild 1 , severe and mild 2) [-],

- $p$ - contact pressure $[\mathrm{MPa}]$,

- $f$ - hardness fraction $H$ over which destruction occurs (seizure),

- $v_{s}$ - sliding (relative) velocity $[\mathrm{m} / \mathrm{s}]$,

- $v_{l, 2}$ - boundary velocities, in which the wear coefficients are changing from mild 1 to severe and back to mild $2[\mathrm{~m} / \mathrm{s}]$.

The sliding distance is calculated from actual output step. The normal force, pressure and sliding (relative) velocity are selected from wheel-rail contact elements. The typical values for wear coefficients are used in literature like: $k_{1}=300-400 \cdot 10^{-4}, k_{2} \approx k_{4}=1-10 \cdot 10^{-4}$ and $k_{3}=30-40 \cdot 10^{-4}$.

\section{Preparation of simulation}

For the simulation of wear was necessary create the most accurate model of the vehicle so that the simulation showed the best possible match with the actual vehicle on the real track. The SIMPACK software has been selected as a suitable solution for this simulation, which enables us to achieve the desired behaviour of the vehicle with its characteristic features. The software allows for a quick and comfortable assembly of the MBS (Multibody Simulation) model of a rail vehicle that meets the wheel-rail contact specifications.

The computational model is characterized by vehicle parameters, geometric and weight parameters, elastic parameters of springs and dampers, and the like. Additionally, they are the parameters of the contact between wheel and rail and the track parameters $[2,13,14]$. This article presents results for one vehicle model (Fig. 1) Model A.

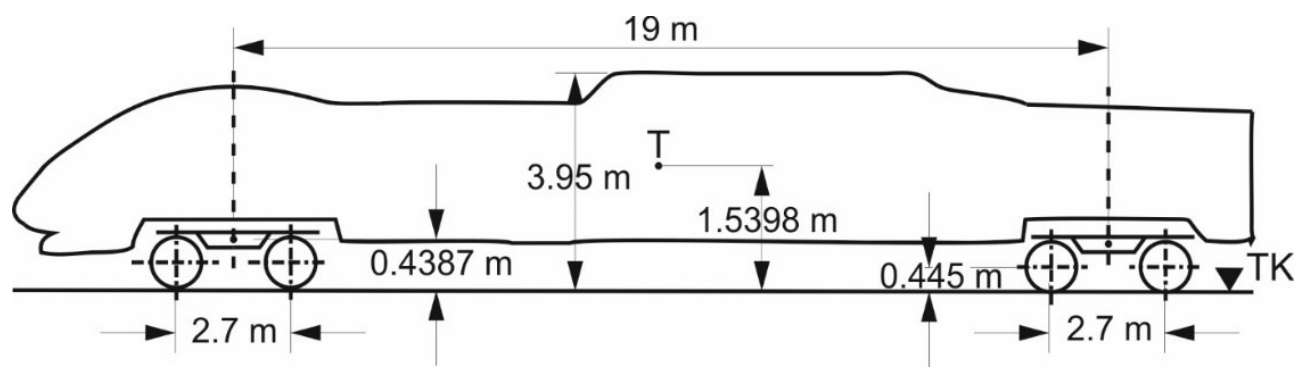

Fig. 1. Schematic sketch of the vehicle (Model A)

The weight parameters, elastic parameters of springs and dampers and geometrical parameters of the vehicle are described in following tables.

Table 1. The weight parameters (Model A)

\begin{tabular}{|c|c|c|c|c|}
\hline & $\boldsymbol{m}[\mathbf{k g}]$ & $\boldsymbol{I}_{\boldsymbol{x} \boldsymbol{x}}\left[\mathbf{k g} \cdot \mathbf{m}^{2}\right]$ & $\boldsymbol{I}_{\boldsymbol{y} \boldsymbol{y}}\left[\mathbf{k g} \cdot \mathbf{m}^{\mathbf{2}}\right]$ & $\boldsymbol{I}_{z z}\left[\mathbf{k g} \cdot \mathbf{m}^{\mathbf{2}}\right]$ \\
\hline Wheelset & 911.312 & 478.686 & 79.27 & 478.686 \\
\hline Bogie Frame & 1157 & 1045.471 & 1127.256 & 2094.2 \\
\hline Vehicle Casing & 22,234 & $39,607.409$ & $1,303,000$ & $1,294,000$ \\
\hline
\end{tabular}

Table 2. Elastic parameters of springs and dampers (Model A)

\begin{tabular}{|c|c|c|c|}
\hline Springing & $\boldsymbol{c}_{\boldsymbol{x}}\left[\mathbf{N} \cdot \mathbf{m}^{-\mathbf{1}}\right]$ & $\boldsymbol{c}_{\boldsymbol{y}}\left[\mathbf{N} \cdot \mathbf{m}^{-\mathbf{1}}\right]$ & $\boldsymbol{c}_{z}\left[\mathbf{N} \cdot \mathbf{m}^{-\mathbf{1}}\right]$ \\
\hline Primary Springing & $608,025.44$ & $608,025.44$ & $695,678.15$ \\
\hline Secondary Springing & $468,148.5231$ & $468,148.5231$ & $604,452.96$ \\
\hline Damping & $\boldsymbol{d}_{\boldsymbol{x}}\left[\mathbf{N} \cdot \mathbf{s} \cdot \mathbf{m}^{-\mathbf{1}}\right]$ & $\boldsymbol{d}_{\boldsymbol{y}}\left[\mathbf{N} \cdot \mathbf{s} \cdot \mathbf{m}^{-\mathbf{1}}\right]$ & $\boldsymbol{d}_{z}\left[\mathbf{N} \cdot \mathbf{s} \cdot \mathbf{m}^{-1}\right]$ \\
\hline Primary Springing & 5000 & 5000 & 17,700 \\
\hline Secondary Springing & 100 & 100 & 34,340 \\
\hline
\end{tabular}


Table 3. The geometrical parameters of vehicle (Model A)

\begin{tabular}{|l|c|c|c|}
\hline \multicolumn{1}{|c|}{ Parameter } & Description & Value & Dimension \\
\hline $\begin{array}{l}\text { The transverse distance of activities of } \\
\text { primary springing and damping }\end{array}$ & 2 & {$[\mathrm{~m}]$} \\
\hline $\begin{array}{l}\text { The transverse distance of activities of } \\
\text { secondary springing and damping }\end{array}$ & & 2 & {$[\mathrm{~m}]$} \\
\hline The distance of rotary pin of bogies & & 19 & {$[\mathrm{~m}]$} \\
\hline $\begin{array}{l}\text { The wheelbase of bogies } \\
\text { Nominal wheel diameter }\end{array}$ & 2.7 & {$[\mathrm{~m}]$} \\
\hline $\begin{array}{l}\text { Height of center of gravity for wheelset } \\
\text { above TK }\end{array}$ & 0.89 & {$[\mathrm{~m}]$} \\
\hline $\begin{array}{l}\text { Height of center of gravity for bogie frame } \\
\text { above TK }\end{array}$ & 0.445 & {$[\mathrm{~m}]$} \\
\hline $\begin{array}{l}\text { Height of center of gravity for vehicle casing } \\
\text { above TK }\end{array}$ & & 0.4387 & {$[\mathrm{~m}]$} \\
\hline Height of the primary springing above TK & & 1.5398 & {$[\mathrm{~m}]$} \\
\hline Height of the secondary springing above TK & & 0.345 & {$[\mathrm{~m}]$} \\
\hline Wheel profile & S1002 & 0.39 & {$[\mathrm{~m}]$} \\
\hline Rail gauge & & 1435 & {$[\mathrm{~mm}]$} \\
\hline Frictional coefficient & $\mu$ & 0.4 & {$[-]$} \\
\hline
\end{tabular}

\subsection{Track parameters}

The model of track consists from the straight sections, clothoid transitions and superelevations segments in the curves of the track. Fig. 2 shows the horizontal track profile, which were by wear simulation used with aim to determine the wear of the vehicle on the track. The length of the model track is $400 \mathrm{~km}$ and from picture is clearly that the profile is very diverse. The track consists from 24 right and 24 left curves of track, the vehicle runs in straight track overall $366 \mathrm{~km}$ and $44 \mathrm{~km}$ in curves of track. The superelevations of the outer ribbon in the curves of track are for each curve of another value. The model track it is not considered like ideally horizontally and vertically straight, in the simulation is considered lateral and vertical irregularities on track too. The irregularities cause the excitations of dynamics system by driving the vehicle on the track and are mostly stochastic.

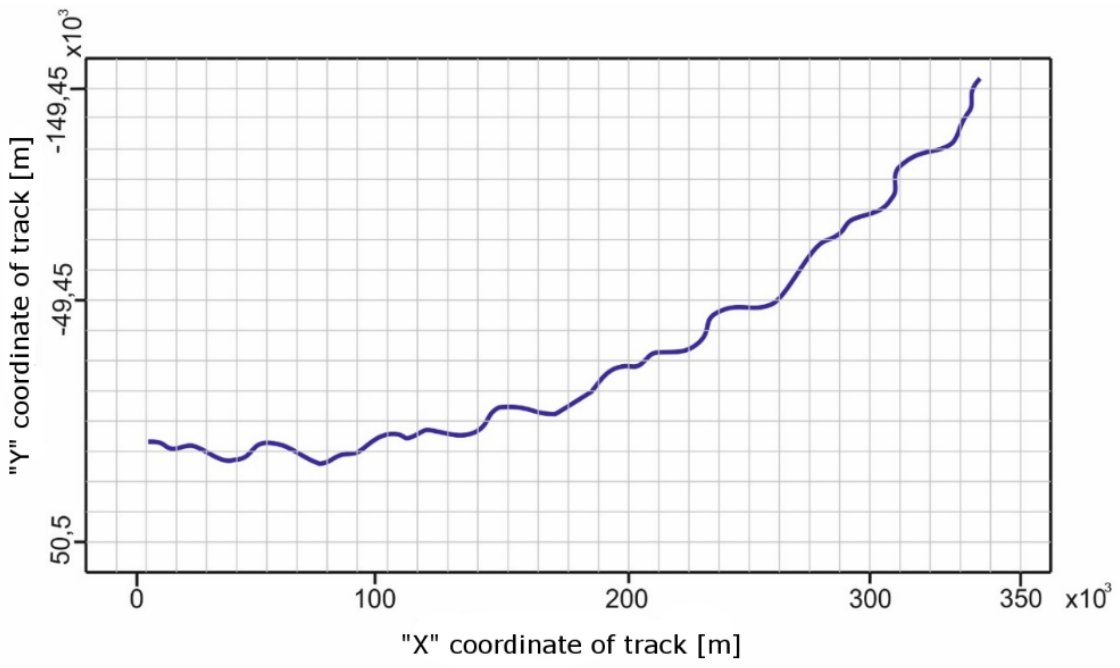

Fig. 2. Horizontal track profile 
The Fig. 3 shows the rail profiles which were used by wear simulations. All the analyses are comply to condition, that the vehicle was traveling along track where the rail profile was defined by standard (UIC 60 profile) with cant of 1:40, or the track profile really measured on the track, the profile S 91700_16 with the cant of 1:20.
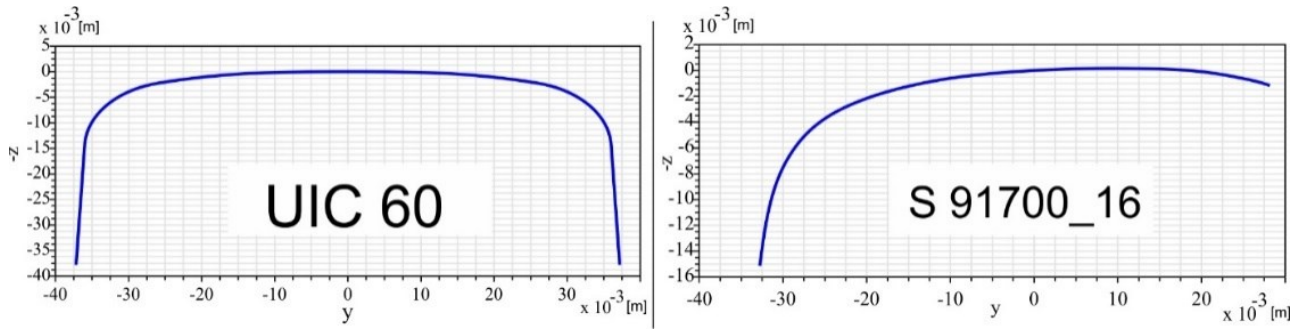

Fig. 3. The rail profiles

\section{Simulations and evaluation of results}

The wear simulation process was chosen for the different distance travelled along the track by the following scheme:

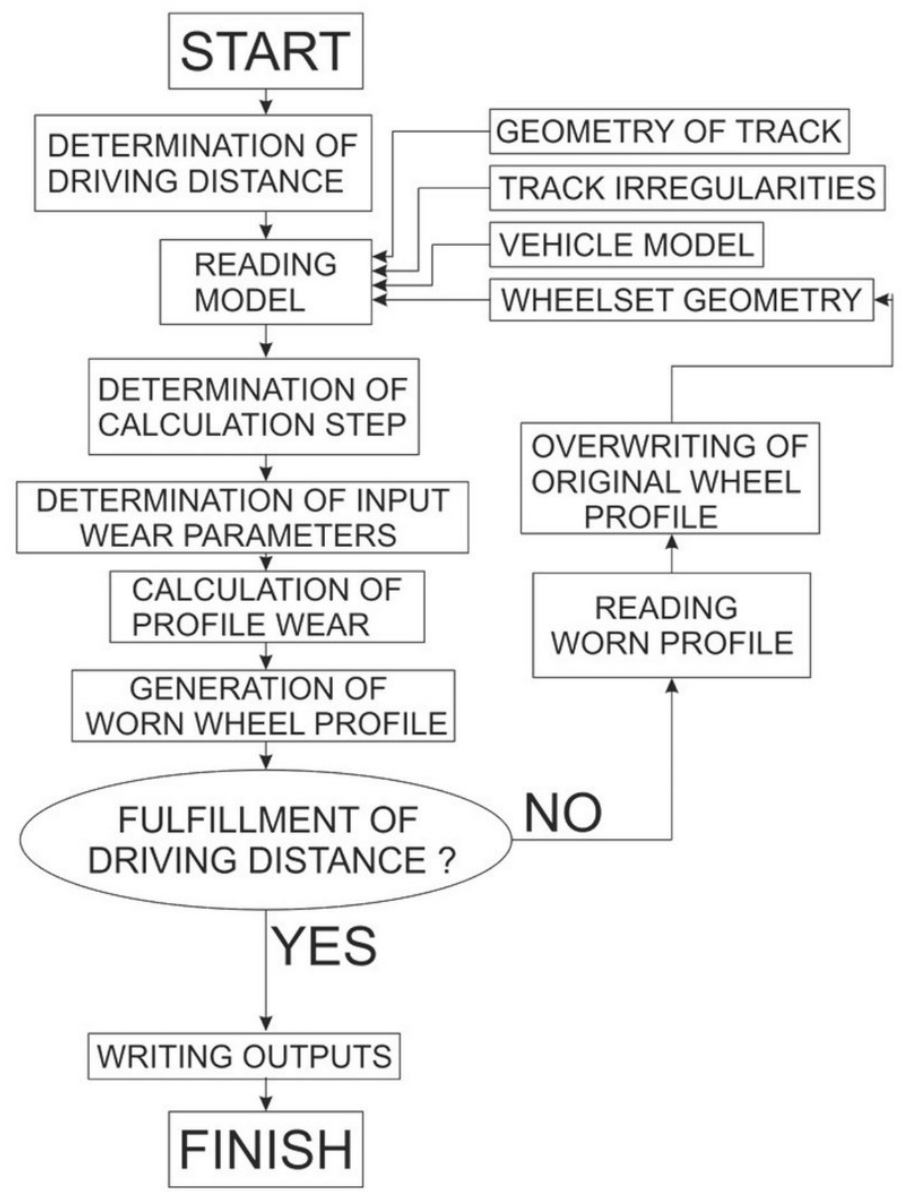

Fig. 4. Wear simulation scheme 
The data flow from Start to Finish can be controlled by programmed cycle or the user can control it manually. The programmed cycle has a significant contribution to simulation mainly in terms of time, but has a huge disadvantage in the necessity of building such a cycle. For this reason, we have managed this data flow described on display scheme (Fig. 4) by entering the necessary condition manually.

The simulations was performed in two variants, by driving the vehicle Model A on the track (Fig.2) with rail profile UIC 60 (Fig.3 left) or rail profile S 91700_16 (Fig. 3 - right). The vehicle velocity was constantly set at $30 \mathrm{~m} / \mathrm{s}$ which is $108 \mathrm{~km} / \mathrm{h}$. The wear coefficients for Archard wear law was chosen from the range of values displayed in the Table 4. It was performed total of 30 analyses, 15 for one rail profile and 15 for the second rail profile. The distance overtaken by the vehicle in one analysis was set at $8000 \mathrm{~km}(400 \cdot 20 \mathrm{~km})$, in total the vehicle was travelled $120,000 \mathrm{~km}(8000 \mathrm{~km}$ times 15 analyses $)$. The computational time was for one analyses around 59 hours CPU time. The results was processed after each fifth analysis, that is after departing 40,000 km, 80,000 km and 120,000 km.

Table 4. The wear coefficients used in analysis

\begin{tabular}{|c|c|c|}
\hline Wear & \multicolumn{2}{|c|}{ Archard law } \\
\hline & theoretical & modified \\
\hline C mild 1 & 0.0005 & 0.0000833 \\
\hline C mild 2 & 0.0005 & 0.0000833 \\
\hline C severe & 0.0035 & 0.000583 \\
\hline C seizure & 0.035 & 0.005833 \\
\hline Distance factor & 20 & 20 \\
\hline
\end{tabular}

On following figures (Fig. 5 and Fig. 6) are displayed the curves of wear depth for two rail variants (UIC 60 and S 91700_16. The black curve represents wear depth after departing $40,000 \mathrm{~km}$, blue curve represents wear depth after departing 80,000 km and red curve represents wear depth after departing $120,000 \mathrm{~km}$. The wear depth value were subtracted during processing from theoretical standardized profile S1002.

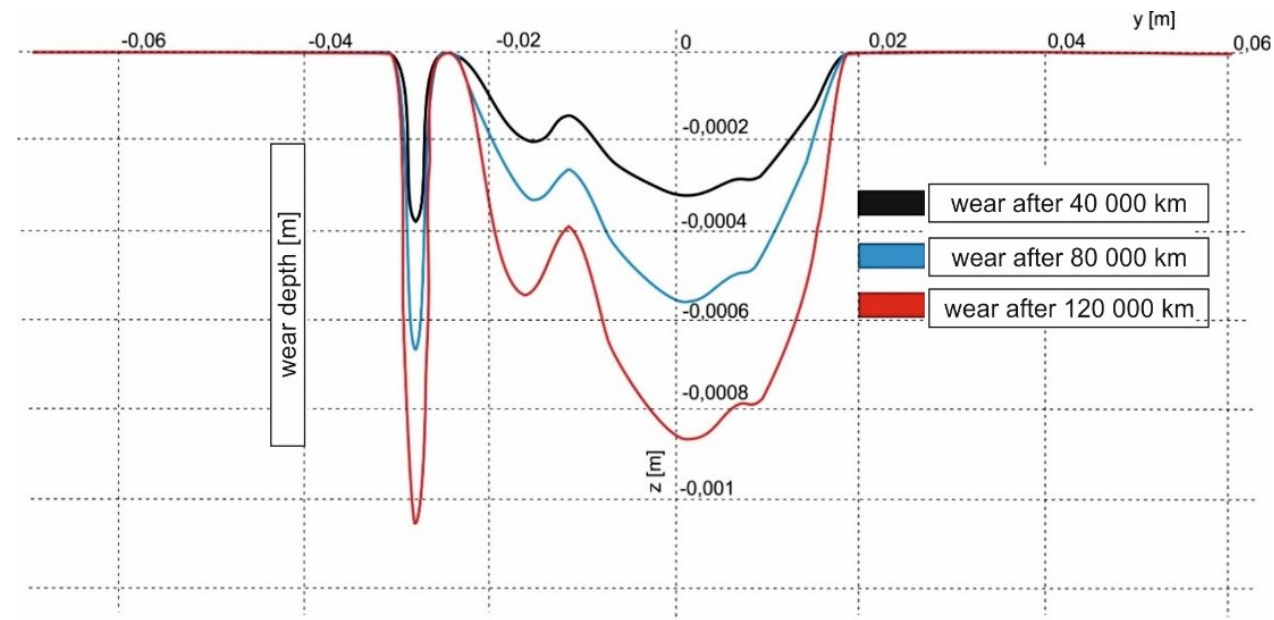

Fig. 5. The wear depth for Model A by driving on the UIC 60 rail profile 


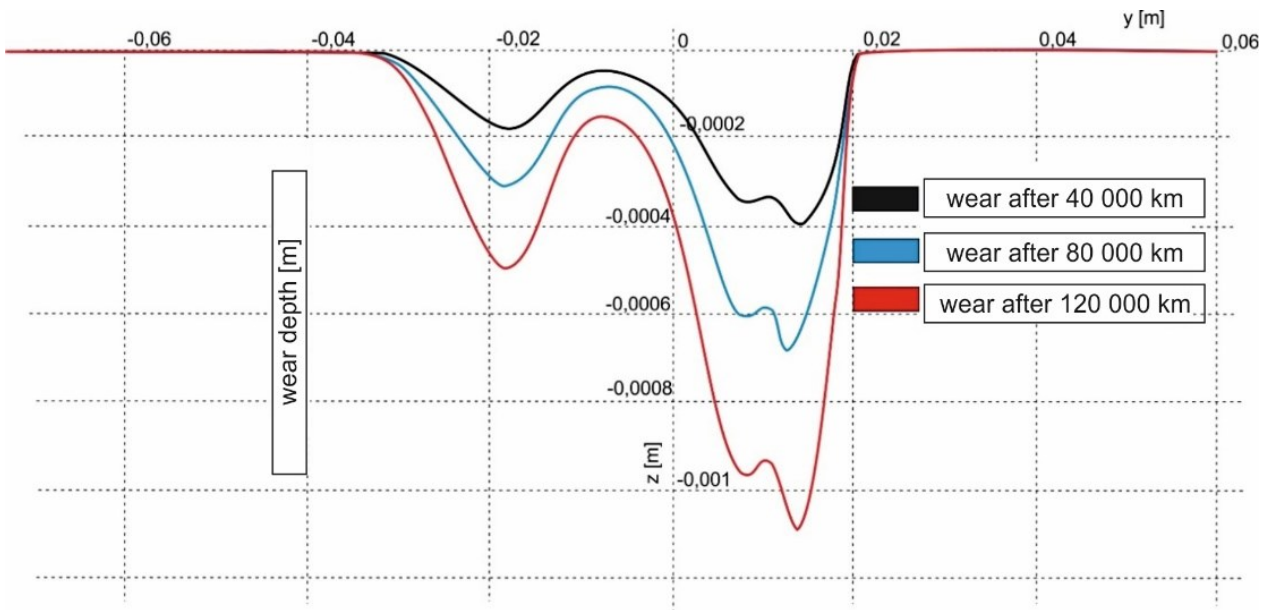

Fig. 6. The wear depth for Model $A$ by driving on the $S 91700 \_16$ rail profile

On following figures (Fig. 7 and Fig. 8) are displayed the curves of worn profiles by departing 40,000 km (blue curve), 80,000 km (green curve) and 120,000 km (red curve) compared to the original theoretical profile S 1002 (black curve). Fig. 7 represents worn profiles where the simulated vehicle Model A driving on the track with UIC 60 rail profile, with rail cant 1:40. Fig. 8 represents worn profiles where the simulated vehicle Model A driving on the track with measured S 91700_16 rail profile, with rail cant 1:20.

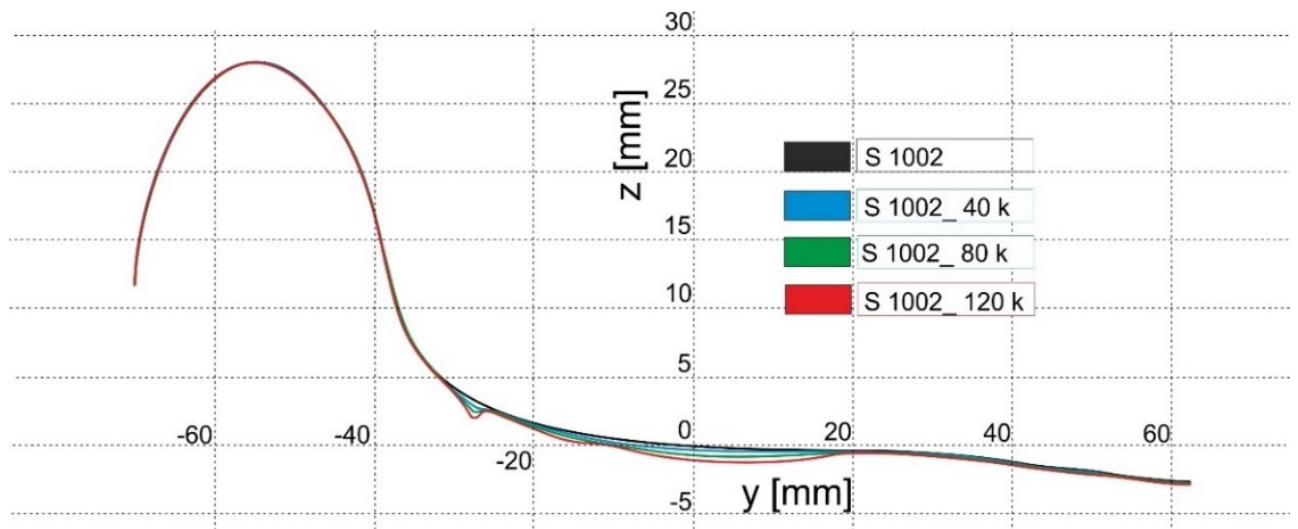

Fig. 7. The worn profiles by driving on the UIC 60 rail profile 


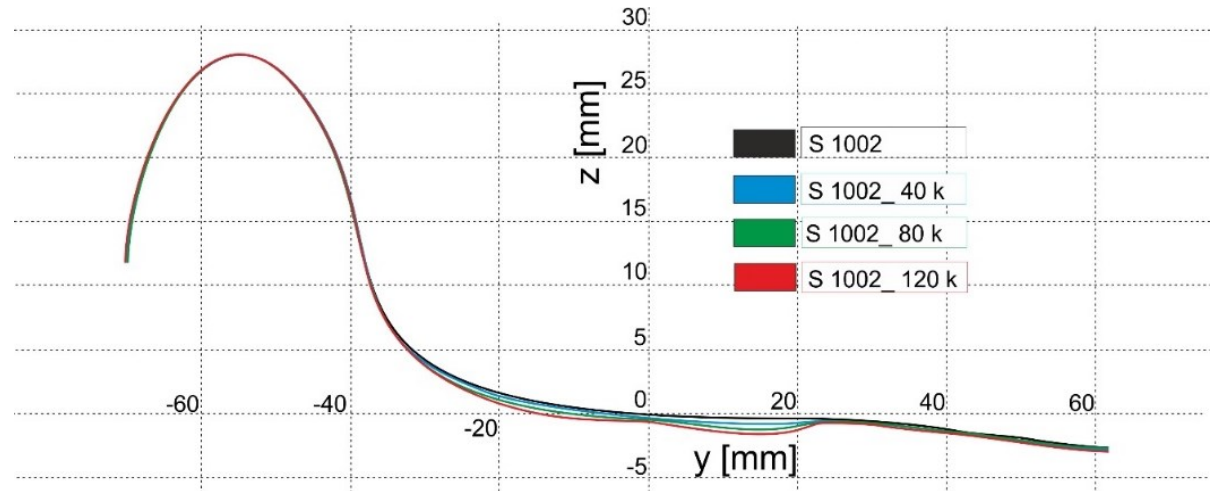

Fig. 8. The worn profiles by driving on the $S 91700 \_16$ rail profile

In Fig. 7 we can notice near to wheel flange the irregularity of worn profile, which would not be possible in real traffic. This irregularity presents in each displayed curves (after $40,000 \mathrm{~km}$, after $80,000 \mathrm{~km}$ and after $120,000 \mathrm{~km}$ ) we assign to numerical calculation error. During simulation occurs the change the transverse position of wheelset in the track. For this reason changes the contact area and contact stress has a higher value. By the calculating with Archard wear law (Eq. 2) occurs multiplication with higher value of contact stress and arises the irregularity which would not be possible in real traffic. Another factor of irregularity is the change of sliding velocity by driving in the curves of track. In Fig. 9 we can notice the change of sliding velocity by driving in the curves of track where is obvious that higher values of the longitudinal sliding velocity are present in the peak by driving at theoretical UIC 60 rail profile. For the curve of track with radius $\mathrm{R} 700$ (p) is the peak of longitudinal sliding velocity higher than $0.8 \mathrm{~m} / \mathrm{s}$, which is boundary value for the change wear coefficient from mild to severe. For this reason are variables in that area multiplied with 10 -times value. This also has a significant impact on the numerical error that has occurred. This numerical error is not occur in Fig. 8 by driving on the track with measured S 91700_16 rail profile.

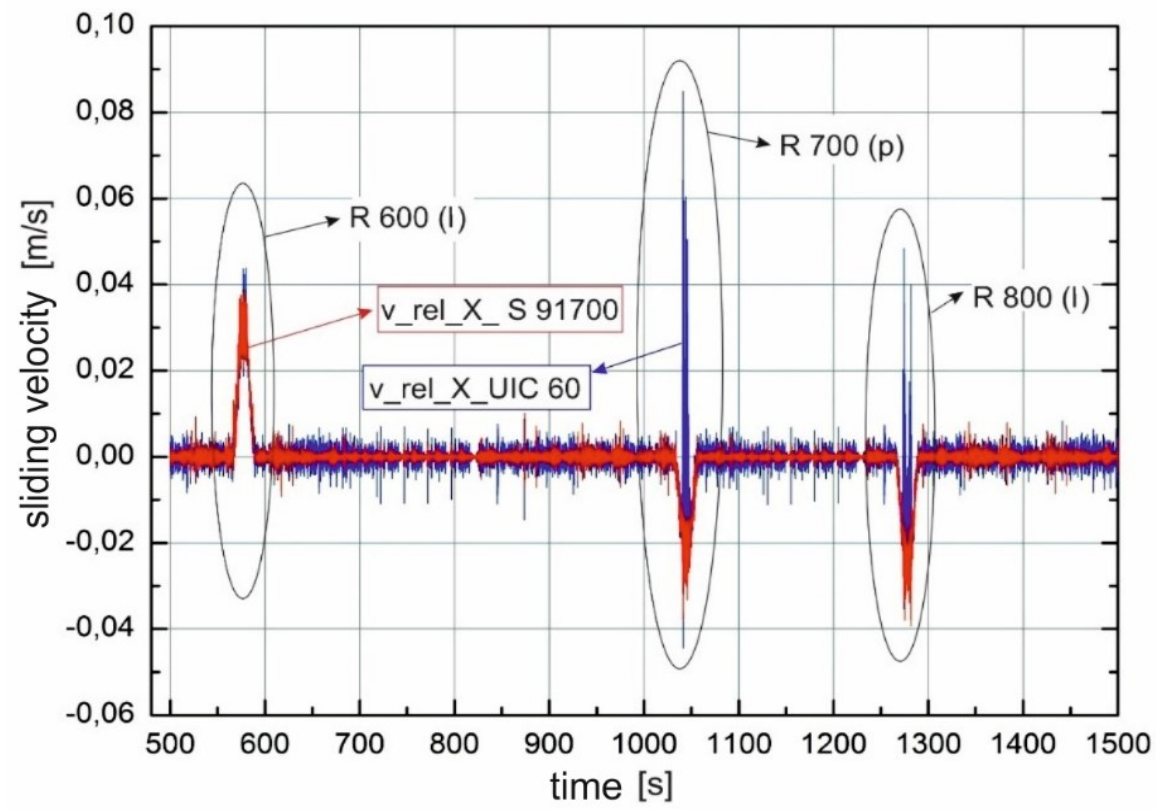

Fig. 9. The longitudinal sliding velocities by driving in the curves of track 


\section{Conclusion}

This article is aimed to the simulation model of railway wheel wear. The motivation to create such a model was the fact that the impact of wear affects the geometrical characteristics of the contact pair, the change of force and slip ratios in contact area, extends to the acoustic and vibration driving behavior which by rising the negative side disrupts the environment surrounding the tracks. In the article are presented the results of wear simulations for the vehicle Model A, which travelled at the constant velocity along the track. It is important to note, that in the simulations the impact of the starting and braking of the railway vehicle is neglected.

This study was supported by Ministry of Education, Science, Research and Sport under the contract No. 1/0595/18 - Optimising the internal geometry of roller bearings with line contact in order to increase their durability and reduce their structural weight.

\section{References}

1. C. I. Barbinta, et al., Wheel-rail contact modelling and analysis, considering profiles types and lateral displacement. Transport Research Arena: 5th Conference: Transport Solutions from Research to Deployment. Paris: 14.04.2014 - 17.04.2014. France: Paris. Accession Number: 01540797 (2014)

2. J. Gerlici, T. Lack, Contact of rail wheelset and track: Žilina: University of Žilina, EDIS, 200 (2004), ISBN 80-710000-317-5

3. R. Enblom, M. Berg, Simulation of railway wheel profile development due to wear influence of disc braking and contact enviroment. Wear: an international journal on the science and technology of friction, lubrication and wear 258, 1055-1063 (2004), ISSN: 0043-1648

4. S. Gramblička, R. Kohár, M. Stopka, Dynamic analysis of mechanical coveyor drive system. Procedia Engineering 192, 259-264. (2017), ISSN 1877-7058

5. M. Tomášiková, T. Gajdošík, M. Lukáč, F. Brumerčík, Simulation of planetary gearbox. Comunications: scientific letters of the University of Zilina 19 (2A), 48-53 (2017), ISSN $1335-4205$

6. Z. Pelagić, M. Nágel', M. Žmindák, D. Riecky, Wear simulation modeling by using the finite element method. Manufacturing technology: Journal for science, research and production 15 (2), 191-195 (2015), ISSN 1213-2489

7. I. I. Argatov, Y. A. Fadin, Mathematical Modeling of the Periodic Wear Process in Elastic Contact between Two Bodies. Journal of Friction and Wear 29 (2), 81-85 (2008), ISSN: 1068-3666

8. T. G. Paerce, N. D. Sherrat, Prediction of wheel profile wear. Wear 144, 343-351 (1991), ISSN: 0043-1648

9. M. Svoboda, J. Soukup, Dynamic Measurement of Four-Axle Railway Wagon. Manufacturing technology: Journal for science, research and production 13 (4), 552-558 (2013), ISSN 1213-2489

10. T. Lack, J. Gerlici, The FASTSIM method modification in speed up the calculation of tangential contact stresses between wheel and rail. Manufacturing technology: Journal for science, research and production 13 (4), 486-492 (2013), ISSN 1213-2489

11. T. Lack, J. Gerlici, Contact area and normal stress determination on railway wheel / rail contact. Communications - scientific letters of the University of Žilina 7 (2), 38-45 (2005), ISSN 1335-4205 
12. P. Pecháč, M. Sága, Controlling of local search methods' parameters in memetic algorithms using the principles of simulated annealing. Procedia Engineering 136, 7076 (2016)

13. J. Dižo, S. Steišunas, M. Blatnický, Vibration analysis of a coach with the wheel-flat due to suspension parameters changes. Procedia Engineering 192, 107-112. (2017), ISSN 1877-7058

14. V. Hauser, et al., Impact of three axle boxes bogie to the tram behavior when passing curved track. Procedia Engineering 192, 295-300. (2017), ISSN 1877-7058 